\title{
Can we improve the diagnosis of early stages of acute kidney injury in hospitalised dogs?
}

\author{
Oscar Cortadellas
}

THE concept of acute renal failure (ARF) has undergone significant re-examination in recent years. Practitioners traditionally used the term to refer to patients presenting with clinical manifestations of uremic syndrome and severe acute azotaemia, and it was often considered to be synonymous with acute kidney disease (AKD). However, it is now accepted that AKD is more than just ARF.

AKD represents a spectrum of diseases associated with a sudden onset of renal parenchymal injury, which are clinically imperceptible at the earliest stages and often end in severe ARF requiring renal replacement therapy. As such, animals diagnosed with ARF represent only the subset of AKD patients with the highest morbidity and mortality. ${ }^{1,2}$

In an attempt to better reflect the broad spectrum of AKD, the term 'acute kidney injury (AKI)' was coined, first in human medicine and then in veterinary medicine. In order to define and stratify the severity of AKI, several grading schemes have been proposed in human nephrology, ${ }^{3}$ and these have subsequently been adapted for veterinary patients (Table 1$)^{1,4}{ }^{1,4}$ These grading systems also include prerenal and postrenal conditions that may be independent of, or coexistent with, intrinsic kidney disease.

In contrast to the 'stability' of chronic kidney disease (CKD) stages, AKI grades represent a moment in the course of the disease, and the grading will change as the condition worsens, improves or transitions to CKD. ${ }^{2}$ Therefore, serial assessment and sequential grading are needed to monitor the course of the disease and to update therapeutic decisions and outcomes. ${ }^{2}$

Although AKI in companion animals typically develops outside of the hospital setting, there has been increasing recognition of this condition in veterinary emergency and critical care medicine in recent years. ${ }^{2}$ In 2011, Thoen and Kerl $^{5}$ reported that 14.6 per cent $(n=164)$ of dogs

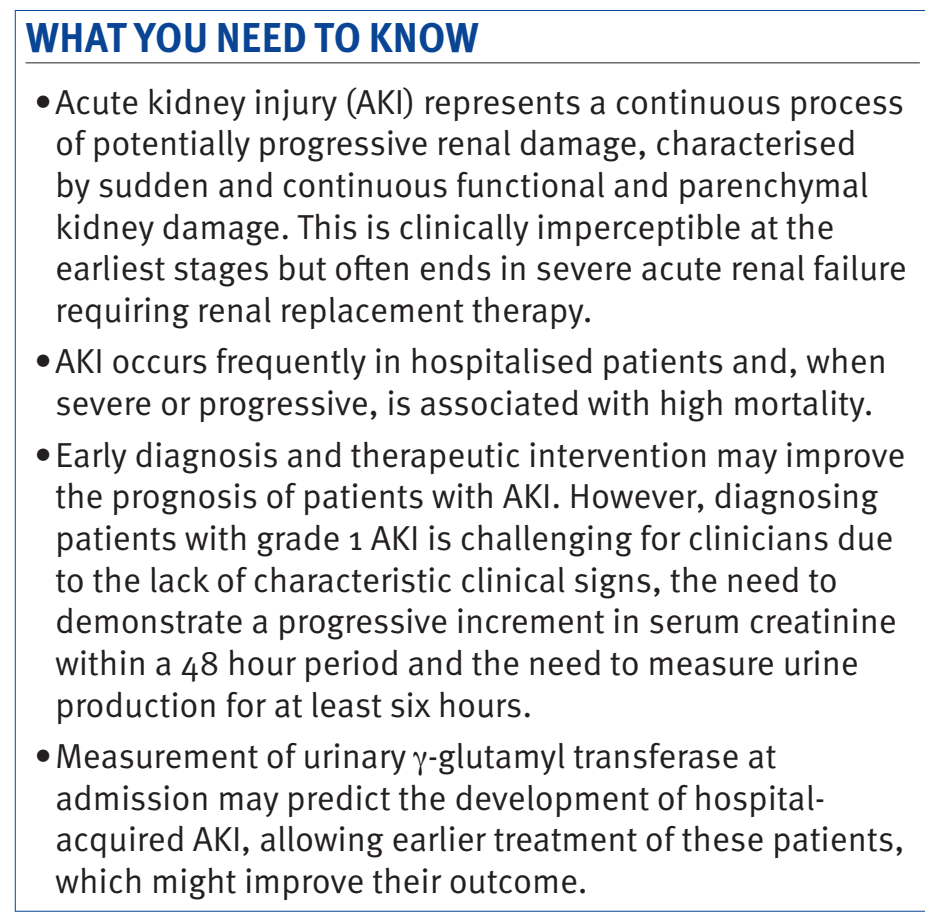

admitted to an intensive care unit developed AKI, as defined by an increase in serum creatinine ( $\mathrm{Cr}$ ) concentration of at least 150 per cent compared with baseline or an absolute $\mathrm{Cr}$ increase of $0.3 \mathrm{mg} / \mathrm{dl}$ or more, during the hospital stay. These authors considered that small increases in serum Cr concentrations might be clinically relevant, even when absolute values were within reference intervals.

In another retrospective study, ${ }^{6} 15$ to 20 per cent of dogs with at least two $\mathrm{Cr}$ measurements taken within a two-, three- or seven-day period $(\mathrm{n}=400$, 476 and 645 , respectively) developed AKI, as defined by an increase in serum $\mathrm{Cr}$ concentration of $0.3 \mathrm{mg} / \mathrm{dl}$ or more. The study concluded that the severity of azotaemia predicts mortality, with a positive relationship existing between serum $\mathrm{Cr}$ levels and mortality at 30 and 90 days.

A recent meta-analysis of dogs with AKI $(n=800)$ has reported a pooled mortality rate of 45 per cent, regardless of treatment type 


\section{RESEARCH COMMENT}

\begin{tabular}{|c|c|c|}
\hline \multicolumn{3}{|c|}{$\begin{array}{l}\text { Table 1: International Renal Interest Society acute kidney injury (AKI) grading scheme for dogs } \\
\text { and cats }{ }^{4}\end{array}$} \\
\hline AKI grade * & Serum creatinine & Clinical description \\
\hline 1 & $\begin{array}{l}<1.6 \mathrm{mg} / \mathrm{dl} \\
(<140 \mu \mathrm{mol} / \mathrm{l})\end{array}$ & $\begin{array}{l}\text { Non-azotaemic AKI: } \\
\text { Documented AKI - historical, clinical, laboratory or imaging evidence of AKI, } \\
\text { clinical oliguria/anuria, volume responsiveness } \dagger \\
\text { Progressive non-azotaemic increase in serum creatinine } \geq 0.3 \mathrm{mg} / \mathrm{dl}(\geq 26.4 \\
\mu \mathrm{mol} / \mathrm{l}) \text { within } 48 \mathrm{hours} \\
\text { Measured oliguria }(<1 \mathrm{ml} / \mathrm{kg} / \mathrm{h}) \text { or anuria over six hours }\end{array}$ \\
\hline 2 & $\begin{array}{l}1.7-2.5 \mathrm{mg} / \mathrm{dl} \\
(141-220 \mu \mathrm{mol} / \mathrm{l})\end{array}$ & $\begin{array}{l}\text { Mild AKI: } \\
\text { Documented AKI and static or progressive azotaemia } \\
\text { Progressive azotaemic increase in serum creatinine } \geq 0.3 \mathrm{mg} / \mathrm{dl}(\geq 26.4 \\
\mu \mathrm{mol} / \mathrm{l} \text { ) within } 48 \text { hours or volume responsiveness } \\
\text { Measured oliguria }(<1 \mathrm{ml} / \mathrm{kg} / \mathrm{h} \text { ) or anuria over six hours }\end{array}$ \\
\hline 3 & $\begin{array}{l}2.6-5 \mathrm{mg} / \mathrm{dl} \\
(221-439 \mu \mathrm{mol} / \mathrm{l})\end{array}$ & \multirow{3}{*}{$\begin{array}{l}\text { Moderate to severe AKI: } \\
\text { Documented AKI and increasing severities of azotaemia and functional renal } \\
\text { failure }\end{array}$} \\
\hline 4 & $\begin{array}{l}5.1-10 \mathrm{mg} / \mathrm{dl} \\
(440-880 \mu \mathrm{mol} / \mathrm{l})\end{array}$ & \\
\hline 5 & $\begin{array}{l}>10 \mathrm{mg} / \mathrm{dl} \\
(>880 \mu \mathrm{mol} / \mathrm{l})\end{array}$ & \\
\hline \multicolumn{3}{|c|}{$\begin{array}{l}\text { * Each AKI grade is further subgraded on the basis of current urine production and on the requirement for renal } \\
\text { replacement therapy } \\
\text { † Volume responsiveness is an increase in urine production to more than } 1 \mathrm{ml} / \mathrm{kg} / \mathrm{h} \text { over six hours and/or a decrease } \\
\text { in serum creatinine to baseline over } 48 \text { hours }\end{array}$} \\
\hline
\end{tabular}

tubule, luminal side) are considered to have the greatest activity. ${ }^{13}$ As GGT is too large to be filtered through a normal glomerulus, a rise in its urinary activity is typically caused by acute damage to the tubules and leakage from the tubular cells. ${ }^{13}$ ${ }^{14}$ Measurement of urinary GGT (uGGT) activity is simple, widely available and cost-efficient, so it can be easily applied in the clinical setting.

uGGT has been most extensively investigated in aminoglycoside-induced AKI in dogs, ${ }^{15-16}$ but it has also been investigated in other conditions, including pyometra, ${ }^{17}$ cisplatininduced nephrotoxicity ${ }^{18}$ and

and aetiology. ${ }^{7}$ However, early recognition and therapeutic intervention may improve the prognosis of patients with AKI. ${ }^{8}$ Unfortunately, diagnosing patients with grade $1 \mathrm{AKI}$ is a challenge for practitioners due to the lack of characteristic clinical signs, the need to demonstrate a progressive increment in serum $\mathrm{Cr}$ within a 48 hour period and the need to measure urine production for at least six hours (Table 1, Fig 1).

In addition, serum $\mathrm{Cr}$ concentration is considered to be a poorly sensitive marker of renal function. Its value is affected by several extrarenal factors (eg, lean body condition), and it has a curvilinear inverse relationship with glomerular filtration rate (GFR) - progressively increasing in small increments in AKI grades 1 and 2 while significant reductions in GFR occur at these stages. ${ }^{9}$

The general consensus regarding the poor performance of serum $\mathrm{Cr}$ concentration for the early diagnosis of AKI has prompted the search for more sensitive markers of renal disease. To date, more than 30 candidate biomarkers have been evaluated, but no one of them fulfils the criteria to be considered an ideal biomarker. ${ }^{10-12}$ $\gamma$-Glutamyl transferase (GGT) - a membranebound enzyme that catalyses the transfer of glutamyl groups between peptides and is involved in glutathione reactions - is one of these biomarkers. Many cells have GGT activity, but biliary epithelial cells, pancreatic acinar cells and renal tubular epithelial cells (proximal leishmaniosis, ${ }^{19-20}$ and also in dogs with AKI of unknown aetiology. ${ }^{21-22}$ However, the results of these studies are contradictory. While some authors concluded that uGGT was a sensitive, early urinary biomarker of kidney damage, whose increments precede changes in serum $\mathrm{Cr},{ }^{15-19}$ others found that $\mathrm{uGGT}$ was not a useful biomarker for this purpose. ${ }^{18,21,22}$

These conflicting data may be a consequence of the lack of standardisation and validation of

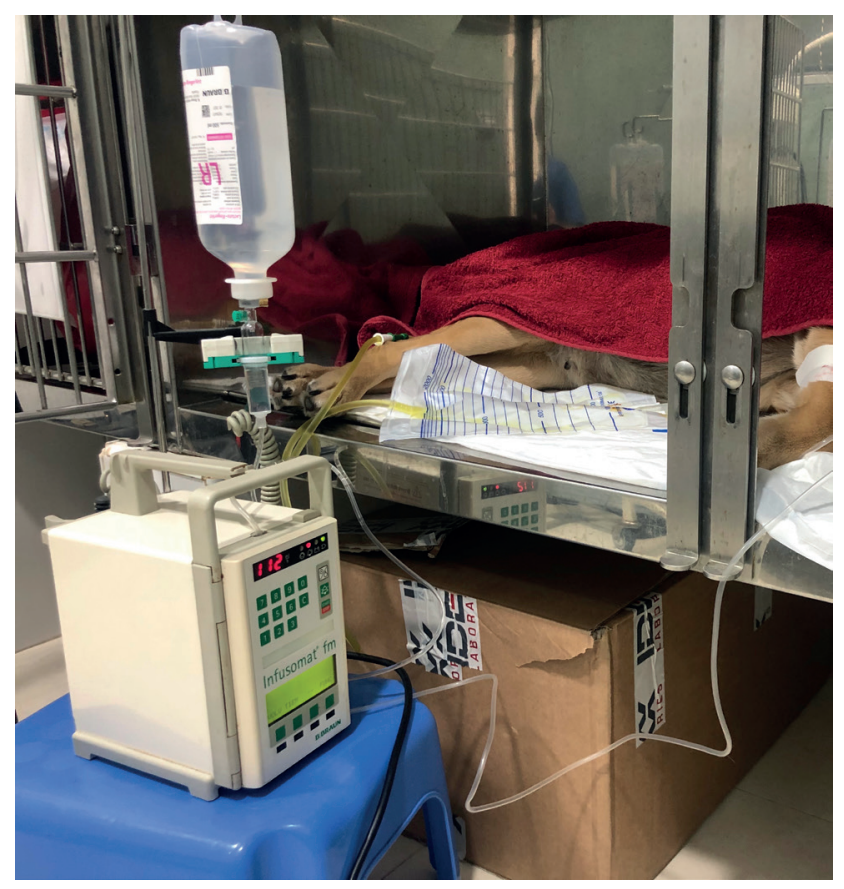

Fig 1: Assessment of urine production (ideally using an indwelling catheter and a closed collection system) is critical for properly grading the severity of acute kidney injury 
the assays used in the different studies, the effect of different variables (ie, sample storage time, pyuria, urine $\mathrm{pH}$, within-day variation), differing causes of AKI in the sampled populations or the variable periods of time elapsing between the occurrence of renal injury and the uGGT measurement in each study. ${ }^{11,12,14,21,22}$ However, despite the conflicting data obtained in these studies, the authors seem to agree that the maximum benefit of using uGGT as an early marker of AKI would be obtained at the earliest stages of the disease - when the patient is first admitted to hospital and before increases in standard serum markers of kidney function are observed. $^{22-24}$

In a study summarised on $\mathrm{p} x \mathrm{xx}$ of this issue of Vet Record, Peronti and colleagues prospectively investigated the usefulness of measuring uGGT (in the form of the $\mathrm{uGGT} /$ urinary $\mathrm{Cr}[\mathrm{uCr}]$ index) to predict the development of AKI in a cohort of non-azotaemic dogs admitted to an intensive care unit. ${ }^{25}$ There are some interesting findings in this study that deserve to be considered and could be of interest for practitioners.

The first is the high prevalence of AKI in the studied population (63.9 per cent), which is significantly higher than that previously reported by other authors. ${ }^{6-7}$ This discrepancy may be partly due to different classification criteria being used in this study compared with previous studies. However, this finding also suggests that hospital-acquired AKI may be underdiagnosed in veterinary medicine.

The second is that patients with progressive AKI have a high mortality rate (69.2 per cent). However, no statistically significant difference in mortality rate was found between the dogs with AKI grade 1 and those without AKI. This suggests that AKI mortality rates need to be considered with caution in the context of hospitalised animals.

Finally, but no less importantly, the uGGT/uCr index was found to predict the development of AKI with moderate sensitivity and specificity. Therefore, uGGT measurement at hospital admission could contribute to earlier diagnosis and therapeutic intervention in patients with AKI, thereby improving their outcome. , $24^{24}$ However, before this diagnostic approach may be routinely recommended, it would be advisable to standardise and validate the assays used to measure uGGT and properly evaluate all known variables that may affect the results obtained.
Oscar Cortadellas, DVM, PhD, Acred AVEPA Med Interna

Departamento Medicina y Cirugía Animal, Hospital Clinico Veterinario, Universidad CEU Cardenal Herrera, Valencia, Spain

email: oscar.cortadellas@uchceu.es

doi: 10.1136/vr.l4562

\section{References}

1 Cowgill LD, Langston C. Acute kidney insufficiency. In: Bartges J, Polzin DJ, eds. Nephrology and Urology of Small Animals. Ames: Wiley-Blackwell, 2011:472-523

2 Elliott J, Cowgill LD. Diagnostic algorithms for grading acute kidney injury and staging the chronic kidney disease patient. In: Elliott J, Grauer GF, Westropp $J$, eds. BSAVA Manual of Canine and Feline Nephrology and Urology. 3rd edn. Gloucester: British Small Animal Veterinary Association, 2017:151-60

3 Kidney Disease: Improving Global Outcomes working group. KDIGO clinical practice guideline for acute kidney injury. Kidney Int Suppl 2012; doi: $10.1038 /$ kisup. 2012.2

4 International Renal Interest Society. Grading of acute kidney injury (2016). http://iris-kidney.com/pdf/4_ldc-revised-grading-of-acute-kidney-injury.pdf (accessed 29 June 2019)

5 Thoen ME, Kerl ME. Characterization of acute kidney injury in hospitalized dogs and evaluation of a veterinary acute kidney injury staging system. J Vet Emerg Crit Care 2011;21:648-57

6 Harison E, Langston C, Palma D, et al. Acute azotemia as a predictor of mortality in dogs and cats. / Vet Intern Med 2012;26:1093-8

7 Legatti SAM, El Dib R, Legatti E, et al. Acute kidney injury in cats and dogs: a proportional meta-analysis of case series studies. PLoS One 2018; doi: 10.1371/journal.pone.0190772

8 Guess SC, Grauer GF. Acute kidney injury. In: Elliott J, Grauer GF, Westropp IL, eds. BSAVA Manual of Canine and Feline Nephrology and Urology. 3rd edn. Gloucester: British Small Animal Veterinary Association, 2017:246-53

9 Braun JP, Lefebvre HP, Watson AD. Creatinine in the dog: a review. Vet Clin Pathol 2003;32:162-79

10 Chen LX, Koyner JL. Biomarkers in acute kidney injury. Crit Care Clin 2015;31:633-48

11 Hokamp JA, Nabity MB. Renal biomarkers in domestic species. Vet Clin Pathol 2016;45:28-56

12 Cobrin AR, Blois SL, Kruth SA, et al. Biomarkers in the assessment of acute and chronic kidney diseases in the dog and cat. J Small Anim Pract 2013;54:647-55

13 Goldstein R. Urinary enzyme activity for detection of acute kidney injury. In: Bartges J, Polzin DJ, eds. Nephrology and Urology of Small Animals. Ames: Wiley-Blackwell, 2011:70-2

14 Brunker JD, Ponzio NM, Payton ME. Indices of urine N-acetyl-beta-Dglucosaminidase and gamma-glutamyl transpeptidase activities in clinically normal adult dogs. Am / Vet Res 2009;70:297-301

15 Greco DS, Turnwald GH, Adams R, et al. Urinary gamma-glutamyl transpeptidase activity in dogs with gentamicin-induced nephrotoxicity. Am J Vet Res 1985;46:2332-5

16 Rivers BJ, Walter PA, O’Brien TD, et al. Evaluation of urine gamma-glutamyl transpeptidase-to-creatinine ratio as a diagnostic tool in an experimental model of aminoglycoside-induced acute renal failure in the dog. / Am Anim Hosp Assoc 1996;32:323-36

17 Heiene R, Moe L, Molmen G. Calculation of urinary enzyme excretion, with renal structure and function in dogs with pyometra. Res Vet Sci 2001;70:129-37

18 McDuffie JE, Sablad M, Ma JY, et al. Urinary parameters predictive of cisplatininduced acute renal injury in dogs. Cytokine 2010;52:156-62

19 Pardo-Marín L, Martínez-Subiela S, Pastor J, et al. Evaluation of various biomarkers for kidney monitoring during canine leishmaniosis treatment. BMC Vet Res 2017:13:31

20 Ibba F, Mangiagalli G, Paltrinieri S. Urinary gamma-glutamyl transferase (GGT) as a marker of tubular proteinuria in dogs with canine leishmaniasis, using sodium dodecyl sulphate (SDS) electrophoresis as a reference method. Vet J 2016;210:89-91

21 Heiene R, Biewenga WJ, Koeman JP. Urinary alkaline phosphatase and gamma-glutamyl transferase as indicators of acute renal damage in dogs. J Small Anim Pract 1991;32:521-24

22 Nivy R, Avital Y, Aroch I, et al. Utility of urinary alkaline phosphatase and $\gamma$-glutamyl transpeptidase in diagnosing acute kidney injury in dogs. Vet J 2017;220:43-7

23 Lisowska-Myjak B. Serum and urinary biomarkers of acute kidney injury. Blood Purif 2010;29:357-65

24 Westhuyzen J, Endre ZH, Reece G, et al. Measurement of tubular enzymuria facilitates early detection of acute renal impairment in the intensive care unit. Nephrol Dial Transplant 2003;18:543-51

25 Perondi F, Lippi I, Ceccherini G, et al. Evaluation of urinary p-glutamyl transferase and serum creatinine in non-azotaemic hospitalised dogs. VetRec 2019; doi: 10.1136/vr.104439 